\title{
Modeling The Bone Marrow Microenvironment's Influence on Leukemic Disease
}

Received: June 09, 2015; Accepted: July 29 , 2015; Published: July 31, 2015

The bone marrow microenvironment serves as both the site of initiation of the majority of hematopoietic malignancies and also contributes to maintenance of minimal residual disease by promoting biologically relevant changes in tumor cells. These functional alterations of leukemic cells include, but are not limited to modulation of cell cycle [1,2], regulation of anti-apoptotic signaling cascades [3-6], and influence on metabolic activity [79]. Of clinical relevance, these pathways impact on therapeutic response, making it critical to have robust in vitro systems to interrogate tumor cell interactions with stromal elements of the microenvironment to screen chemotherapeutic agents and inform the in vivo model design.

To generate a model of the marrow microenvironment niche human leukemic cells were co-cultured with human primary bone marrow stromal cells (BMSC). Frequently, applications require separation of tumor cells and stromal components for subsequent western blot, PCR, DNA or RNA based analysis. However, confocal microscopy provides the unique opportunity to study critical tumor: stromal cell interactions in vitro without physically detaching the tumor population prior to evaluation. This approach is valuable given the transient nature of cell signaling that may be immediately altered upon physical removal of leukemic cells from niche derived stroma. With this approach
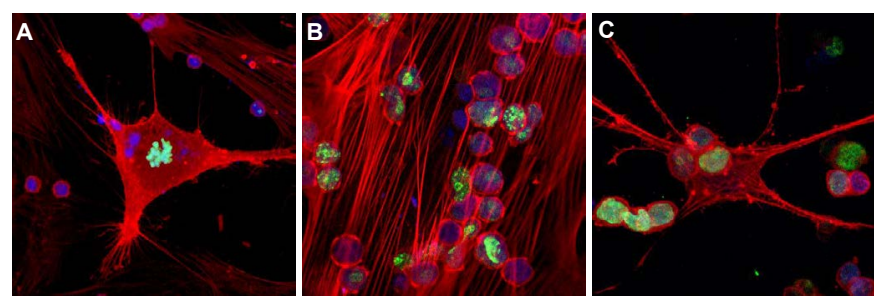

Figure 1

$\mathrm{Ki} 67^{+}$evaluation of human leukemic and bone marrow stromal cells (BMSC).Nalm-27 Ph+ ALL leukemic cells (Fujisaki Cancer Center) co-cultured with a dividing Ki67+ human primary BMSC (A), Nalm-27 cells co-cultured with confluent BMSC representing one structural component of the bone marrow microenvironment (B) and Nalm-27 tumor cells in a 3-dimensional static co-culture with BMSC (C) to model architecture of the niche.

\section{Evans $\mathrm{R}^{1}$, Martin $\mathrm{KH}^{1,2}$, Moses $\mathrm{BS}^{1}$, Slone WL" Hare $\|^{1,3}$, Piktel D ${ }^{1}$, Thomas $\mathrm{P}^{1}$ and Giloson LF1,3}

Corresponding author: Gibson LF

Igibson@hsc.wvu.edu

Mary Babb Randolph Cancer Center, Robert C. Byrd Health Sciences Center, West Virginia University School of Medicine, P.O Box 9300, Morgantown, WV 26506-9300, USA.

Tel: 3042931547

Fax: 3042934667

Citation: Evans R, Martin KH, Moses $\mathrm{BS}$, et al. Modeling The Bone Marrow Microenvironment's Influence on Leukemic Disease. Transl Biomed. 2015, 6:2.

a variety of targets are amendable to evaluation, with Ki67 shown in Figure 1 as just one example.

\section{Funding Source}

NIH NHLBI R01 HL056888 (LFG), NIH NCl R01 CA134573NIH (LFG), P30 GM103488 (LFG), WV CTR-IDEA NIH 1U54 GM104942, the Alexander B. Osborn Hematopoietic Malignancy and Transplantation Program, and the WV Research Trust Fund. 


\section{References}

Boyerinas B (2013) Adhesion to osteopontin in the bone marrow niche regulates lymphoblastic leukemia cell dormancy. Blood 121: 4821-4831.

2 Saito Y (2010) Induction of cell cycle entry eliminates human leukemia stem cells in a mouse model of AML. Nat. Biotechnol 28: 275-280.

3 Bradstock K, Bianchi A, Makrynikola V, Filshie R, Gottlieb D (1996) Long-term survival and proliferation of precursor-B acute lymphoblastic leukemia cells on human bone marrow stroma. Leukemia 10: 813-820.

4 Manabe A (1994) Adhesion-dependent survival of normal and leukemic human B lymphoblasts on bone marrow stromal cells. Blood 83: 758-766.
Tesfai Y (2012) Interactions between acute lymphoblastic leukemia and bone marrow stromal cells influence response to therapy. Leuk. Res 36: 299-306.

6 Mudry RE, Fortney JE, York T, Hall BM, Gibson LF (2000) Stromal cells regulate survival of B-lineage leukemic cells during chemotherapy. Blood 96: 1926-1932.

7 Tiziani S (2013) Metabolomics of the tumor microenvironment in pediatric acute lymphoblastic leukemia. PloS One 8, e82859.

Wu W, Zhao S (2013) Metabolic changes in cancer: beyond the Warburg effect. Acta Biochim Biophys Sin 45: 18-26.

Zhao Y (2008) Glucose metabolism attenuates p53 and Pumadependent cell death upon growth factor deprivation. J. Biol. Chem 283: 36344-36353. 